\title{
Electrophysiological findings of Turkish patients with restless legs syndrome
}

\author{
This article was published in the following Dove Press journal: \\ Neuropsychiatric Disease and Treatment \\ 27 July 2017 \\ Number of times this article has been viewed
}

\author{
Ahmet Özsimsek' \\ Hasan Rifat Koyuncuoglu² \\ 'Neurology Department, Ușak \\ Medical Park Hospital, Ușak, \\ ${ }^{2}$ Neurology Department, Medical \\ Faculty, Süleyman Demirel University, \\ Isparta, Turkey
}

\begin{abstract}
We aimed to investigate changes in electrophysiological findings in Turkish patients with restless legs syndrome (RLS), including F-wave latency (FWL), peripheral silent period (PSP), and Hoffmann reflex. The study took place in a university hospital in Turkey and involved 30 newly diagnosed RLS patients and 30 healthy controls who were matched for age and gender. Participant's demographics (age, gender, weight, and height), laboratory findings, and electrophysiological test outcomes were gathered and analyzed. There was no significant difference in the FWL of the median and ulnar nerves, whereas the H-wave maximum amplitude and $\mathrm{H} / \mathrm{M}$ ratio were significantly higher in the RLS patients than in the controls at rest. All of the PSP parameters were similar between patients and controls for the abductor pollicis brevis and gastrocnemius muscles. However, for the tibialis anterior muscle, all the PSP duration parameters were shorter in the RLS patients, whereas the PSP latency parameters were similar. The data suggest that there may be a reduction in spinal segmental inhibition at the L4-L5-S1 level, but the mechanisms of inhibition at the L4-L5 and S1 levels may be different; furthermore, there may be no pathology in the peripheral nerves. Further prospective studies with larger cohorts are now needed to evaluate the pathophysiology of RLS with different neurophysiological assessment tools.
\end{abstract}

Keywords: restless legs syndrome, F wave, peripheral silent period, Hoffmann reflex

\section{Introduction}

Restless legs syndrome (RLS), also known as Willis-Ekbom disease, is a sensorimotor movement disorder characterized by an uncomfortable sensation in the legs and an irresistible urge to move the legs. Frequently, patients also have motor symptoms such as rhythmic leg movements, referred to as periodic limb movements. ${ }^{1}$ Population-based studies report the prevalence of RLS to be in the range of $1 \%-20 \%$ among different ethnic populations. ${ }^{2-5}$ The symptoms of RLS appear or worsen at nights and during periods of rest or inactivity such as lying or sitting. ${ }^{6}$ Patients with RLS generally consult a physician with sleeplessness because RLS often impairs sleep quality and the quality of life. ${ }^{7}$ Since there is a wide spectrum of symptoms for RLS, ranging from a stressful situation to the total disruption of sleep, the International Restless Legs Syndrome Study Group (IRLSSG) developed an RLS severity rating scale to help evaluate this wide range of symptoms. ${ }^{8}$

Iron metabolism and subsequent dopaminergic dysfunction are probable mechanisms in the pathophysiology of the RLS, although the complete mechanism has not been fully elucidated. ${ }^{9-12}$ RLS can be divided into two forms: primary and secondary forms. In the primary (idiopathic) form, there are not any other disorders that can be related to RLS. The secondary form is attributed to iron deficiency, pregnancy, or end-stage renal disease. ${ }^{10,13}$ Many studies have reported associations between RLS and
Correspondence: Ahmet Özsimsek Neurology Department, Ușak Medikal Park Hospital, Dikilitaș, Atatürk Blv I39/A, 64100 Merkez/Ușak, Turkey Tel +90276227 6565 Fax +902762272233 Email ahmet.ozsimsek@yahoo.com.tr (c) (7) (9) 2017 Özsimsek and Koyuncuoglu. This work is published and licensed by Dove Medical Press Limited. The full terms of this license are available at https://www.dovepress.com/terms.php cc) ${ }_{\mathrm{BY}} \mathrm{NC}$ and incorporate the Creative Commons Attribution - Non Commercial (unported, v3.0) License (http:///creativecommons.org/licenses/by-nc/3.0/). By accessing the work you hereby accept the Terms. Non-commercial uses of the work are permitted without any further permission from Dove Medical Press Limited, provided the work is properly attributed. For permission for commercial use of this work, please see paragraphs 4.2 and 5 of our Terms (https://www.dovepress.com/terms.php). 
a range of different factors, including socioeconomic status, smoking, diabetes, hypercholesterolemia, exercise, body mass index (BMI), and hypertension. ${ }^{14-17}$ Altered responses to transcranial magnetic stimulation (TMS) in sleep disorders, including RLS, have also been reported. Recently published reviews describe RLS as having a tendency to exhibit reduced motor cortex inhibition and is associated with abnormal plasticity-related TMS phenomena and abnormal cortical excitability. ${ }^{18,19}$

To strengthen the clinical diagnosis of RLS, physicians would normally use medical histories and laboratory tests, and also polysomnographic recordings and the suggested immobilization test. ${ }^{1,20}$ However, neurophysiological techniques have been applied to RLS patients to attain direct and indirect measures of central, spinal, and peripheral nervous system excitability. ${ }^{21}$ Electromyography (EMG) and nerve conduction studies (NCS) are also used to document peripheral neuropathy and radiculopathy in patients with RLS. $^{22}$ Isak et $\mathrm{al}^{23}$ diagnosed patients with RLS with the help of F-wave latency (FWL) and the peripheral silent period (PSP), which were assumed to change based on activation and suppression of motoneurons (MNs) in response to the electrical current through the MNs (F-waves), small-fiber sensory neurons (PSP). Rijsman et $\mathrm{al}^{24}$ also reported the existence of abnormal Hoffmann reflexes (H-reflex), which may be changed with the change in the resting excitability of the spinal MNs by the activity in descending and segmental neural pathways in patients with RLS and with periodic limb movement disorder (PLMD). Consequently, in this study, we aimed to determine changes in electrophysiological tests in patients with RLS, including FWL, PSP, and H-reflex.

\section{Methods}

\section{Participants}

This observational study was performed at a University Hospital in Turkey and was approved by the Süleyman Demirel University Institutional Review Board. We included 30 newly diagnosed RLS patients as a patient group, who were admitted to the Neurology Clinic between June 1, 2012, and March 1, 2013. The male/female ratio was 1:1. Cases who met the 2012 Revised IRLSSG diagnostic criteria were defined as patients. ${ }^{25}$ Thirty healthy volunteers were also included in the study as a control group. For each patient, one control was matched for age and gender. Our inclusion criteria were: 1) newly diagnosed with RLS, 2) untreated with any medication, and 3) aged over 18 years. Our exclusion criteria were as follows: neuromuscular disease, abnormal findings upon neurological examination, abnormal NCS findings, renal failure, alcohol addiction, pregnancy, cardiac pacemaker, and/or diabetes.

Initially, all participants were evaluated by a full physical examination, and laboratory tests for fasting glucose, serum iron level, iron-binding capacity, ferritin, magnesium, calcium, free triiodothyronine, free thyroxine, thyroid-stimulating hormone, folic acid, vitamin B12, and urea tests. Participant's demographics (age, gender, weight, and height), laboratory findings, and electrophysiological test outcomes were collated and analyzed.

\section{Electrophysiological examination}

Electrophysiological tests were performed in the Electrophysiology Laboratory in the neurology clinic. A four-channel EMG system (Neuropack MEB 5504 K; Nihon Kohden Corporation, Tokyo, Japan) was used for electrophysiological examination. Initially, for each participant, we carried out two upper extremity motor nerve (median and ulnar) conductions, two upper extremity sensory nerve (median and ulnar) conductions, two lower extremity motor nerve (tibial and peroneal) conductions, and one lower extremity sensory nerve (sural) conduction.

For the NCS, a sensory conduction study was performed in the right sural, ulnar, and median nerves, and a motor conduction was carried out in the right ulnar, median, and tibial nerves. FWL was recorded in the right ulnar, median, and tibial nerves.

H-reflex was elicited by electrical stimulation for $0.2 \mathrm{~ms}$ with a felt pad bar electrode placed on the gastrocnemius muscle with the participant lying in the supine position. The anode of the stimulating electrode was taped on the distal end of the muscle, whereas the cathode was taped on the proximal end. Stimulations were performed initially with $1 \mathrm{~mA}$ and were increased by $1 \mathrm{~mA}$ until the maximal or supra-maximal stimulation intensity was achieved. The recording was performed initially in a resting position and then during forced plantar flexion. Stimulations were applied in irregular intervals of at least 3-5 s. H-reflex maximum amplitude and latency were recorded, along with M-response maximum amplitude and latency. $\mathrm{H} / \mathrm{M}$ ratio was determined as the ratio of maximum H-reflex amplitude to maximum M-response amplitude.

PSP parameters were measured in the right abductor pollicis brevis (APB) muscle in the upper extremity, and in the right tibialis anterior (TA) and gastrocnemius muscles in the lower extremity, when participants were in the supine position. Initially, each participant's pain thresholds were measured by electrical stimuli with a duration of $0.2 \mathrm{~ms}$ and 
intensity was increased from $0.6 \mathrm{~mA}$ from the index finger for the median nerve, from the posterior of the external malleolus for the posterior tibial nerve, and from the anterior of the ankle for the deep peroneal nerve. Pain threshold was defined as the value at which the participant felt pain. Electrical stimuli at an intensity of 15 -fold relative to the pain threshold were applied to the second finger of the right hand with a ring electrode. After the participant made opposition of right thumb, the recording was carried out with the felt pad electrode on the right APB muscle. This procedure was repeated in the middle of the right ankle with a felt pad electrode, while undergoing dorsiflexion of the right foot for the TA muscle, and while undergoing plantar flexion of the right foot for the gastrocnemius muscle. The period of inhibition of electrical stimulation of the maximum motor unit action potential achieved, defined as the PSP, and the time from stimulation to when PSP began was defined as PSP latency, whereas the time taken from the beginning of PSP to the end of PSP was defined as PSP duration. These measurements were repeated five times for each muscle. Using these five repeated measurements, we determined maximum PSP duration, minimum PSP duration, and mean PSP duration (mean of maximum and minimum PSP duration), maximum PSP latency, minimum PSP latency, and mean PSP latency (average of maximum and minimum PSP latency).

\section{Statistical analysis}

Statistical analysis was performed using IBM SPSS Statistics version 13.0 software (SPSS, Inc., Chicago, IL). Mean and standard deviation (SD) were used as descriptive statistics for normally distributed continuous variables. The independent samples $t$-test was used for analysis of parametric continuous data between patient and control groups. A $P<0.05$ was considered statistically significant.

\section{Ethical approval}

This study was approved by our Institutional Review Board and followed the tenets of the Declaration of Helsinki.

\section{Results}

During the study period, 30 patients with RLS were admitted to our hospital. The mean height of the patients and controls was 169.40 and $165.70 \mathrm{~cm}$, respectively. The mean weight of the patients and controls was 76.33 and $70.83 \mathrm{~kg}$, respectively. There were no statistical differences in terms of height or weight between the two groups (Table 1, $P>0.05$ ).

Mean FWL of the median nerve in patients and controls was 27.01 and $27.10 \mathrm{~ms}$, respectively, while that in the
Table I Demographics of the study population

\begin{tabular}{llll}
\hline Demographics & Patients $(\mathbf{n}=\mathbf{3 0})$ & Controls $(\mathbf{n}=\mathbf{3 0})$ & $\boldsymbol{P}$-value \\
\hline Height $(\mathrm{cm})$ & $169.40 \pm 9.87$ & $165.70 \pm 9.76$ & 0.15 \\
Weight $(\mathrm{kg})$ & $76.33 \pm 15.56$ & $70.83 \pm 15.06$ & 0.17 \\
\hline
\end{tabular}

Notes: $P$-value for Student's $t$-test; mean $\pm S D$.

Abbreviation: SD, standard deviation.

ulnar nerve was 26.67 and $27.12 \mathrm{~ms}$. However, mean FWL in the tibial nerve of patients and controls was 42.05 and $42.01 \mathrm{~ms}$, respectively. No statistical differences were found in terms of F-wave responses in the median, ulnar, and tibial nerves when compared between patients and controls (Table 2, $P>0.05$ ).

Data also showed that $\mathrm{M}$-wave maximum amplitude was similar between patients and controls at rest and with forced plantar flexion. However, H-wave maximum amplitude was significantly higher in patients $(1.03 \pm 1.21)$ at rest than controls $(0.53 \pm 0.48)(P=0.04)$, although there was no statistically significant difference between patients and controls during forced plantar flexion. $\mathrm{H} / \mathrm{M}$ ratio was almost two times greater than controls at rest $(P=0.005)$, although there was no statistically significant difference in $\mathrm{H} / \mathrm{M}$ ratio during forced plantar flexion. While mean M-wave latency of patients and controls was statistically similar at rest, data showed that M-wave latency was significantly higher in patients than in controls during plantar flexion $(P=0.01)$. However, there was no statistically significant difference in $\mathrm{H}$-wave latency between patients and controls, either at rest or during forced plantar flexion (Table 3).

Analysis also showed that all of the PSP parameters were not significantly different when compared between patients and controls for the APB and gastrocnemius muscles. However, results were different when we considered the maximum, minimum, and mean PSP duration for the TA muscle; all of these duration parameters were shorter in patients when compared with controls. The maximum PSP duration was 64.98 in controls and 49.64 in patients; the minimum PSP duration was 46.58 in controls and 37.16 in patients; and the mean PSP duration was 55.78 in controls and 43.40 in patients. These differences were all statistically

Table 2 Mean F-wave latency values for the median, ulnar, and tibial nerves

\begin{tabular}{llll}
\hline Nerve & Patients $(\mathbf{n}=\mathbf{3 0})$ & Controls $(\mathbf{n}=\mathbf{3 0})$ & P-value \\
\hline Median $(\mathrm{ms})$ & $27.0 \mathrm{I} \pm 2.59$ & $27.10 \pm 1.73$ & 0.88 \\
Ulnar $(\mathrm{ms})$ & $26.67 \pm 2.05$ & $27.12 \pm 2.30$ & 0.42 \\
Tibial $(\mathrm{ms})$ & $42.05 \pm 4.74$ & $42.0 \mathrm{I} \pm 6.00$ & 0.97 \\
\hline
\end{tabular}

Notes: $P$-value for Student's $t$-test; mean $\pm S D$.

Abbreviation: SD, standard deviation. 
Table $3 \mathrm{H}$-reflex parameters at rest and during forced plantar flexion

\begin{tabular}{|c|c|c|c|c|}
\hline Position & Parameters & $\begin{array}{l}\text { Patients } \\
(n=30)\end{array}$ & $\begin{array}{l}\text { Controls } \\
(n=30)\end{array}$ & $P$-value \\
\hline \multirow[t]{5}{*}{ Rest } & M-wave max amp (mV) & $4.19 \pm 2.30$ & $4.14 \pm 1.49$ & 0.91 \\
\hline & $\mathrm{H}$-wave max amp (mV) & $1.03 \pm 1.21$ & $0.53 \pm 0.48$ & 0.04 \\
\hline & $\mathrm{H} / \mathrm{M}$ ratio & $25.98 \pm 20.46$ & $|3.44 \pm||.8|$ & 0.005 \\
\hline & M-wave latency (ms) & $8.61 \pm 11.09$ & $5.24 \pm 1.55$ & 0.10 \\
\hline & $\mathrm{H}$-wave latency (ms) & $32.54 \pm 2.45$ & $31.77 \pm 2.18$ & 0.20 \\
\hline Forced & M-wave max amp (mV) & $5.76 \pm 3.67$ & $5.32 \pm 2.15$ & 0.57 \\
\hline plantar & $\mathrm{H}$-wave max amp (mV) & $1.5 \mathrm{I} \pm \mathrm{I} .59$ & $1.33 \pm 2.13$ & 0.71 \\
\hline \multirow[t]{3}{*}{ flexion } & $\mathrm{H} / \mathrm{M}$ ratio & $25.06 \pm 17.90$ & $20.57 \pm 19.20$ & 0.35 \\
\hline & M-wave latency (ms) & $6.09 \pm 2.01$ & $4.98 \pm 1.41$ & 0.01 \\
\hline & $\mathrm{H}$-wave latency (ms) & $31.89 \pm 2.74$ & $30.96 \pm 2.26$ & 0.16 \\
\hline
\end{tabular}

Notes: $P$-value for Student's $t$-test; mean \pm SD.

Abbreviations: $\mathrm{H}$-reflex, Hoffmann reflex; max, maximum; SD, standard deviation.

significant ( $P=0.004,0.01$, and 0.005 , respectively). Finally, we found no statistically significant difference in terms of maximum, minimum, and mean PSP latency for the TA muscle (Table 4).

\section{Discussion}

In brief, we found that the height and weight of patients with RLS were similar to healthy controls, and that there were no statistical differences in FWL of the median and ulnar nerves. $\mathrm{H}$-wave maximum amplitude and $\mathrm{H} / \mathrm{M}$ ratio were

Table 4 Peripheral silent period (PSP) parameters for the abductor pollicis brevis (APB), tibialis anterior (TA), and gastrocnemius muscles

\begin{tabular}{lllll}
\hline Muscle & Parameters & $\begin{array}{l}\text { Patients } \\
(\mathbf{n}=\mathbf{3 0})\end{array}$ & $\begin{array}{l}\text { Controls } \\
(\mathbf{n}=\mathbf{3 0})\end{array}$ & P-value \\
\hline APB & Max PSP duration & $55.72 \pm 11.45$ & $59.16 \pm 11.72$ & 0.25 \\
& Min PSP duration & $43.26 \pm 7.75$ & $46.22 \pm 9.75$ & 0.19 \\
& Mean PSP duration & $49.49 \pm 9.04$ & $52.69 \pm 10.49$ & 0.21 \\
& Max PSP latency & $70.40 \pm 11.93$ & $67.06 \pm 11.60$ & 0.27 \\
& Min PSP latency & $76.32 \pm 10.09$ & $74.70 \pm 7.78$ & 0.49 \\
Gastrocnemius & Mean PSP latency & $73.36 \pm 10.62$ & $70.88 \pm 9.05$ & 0.33 \\
& Min PSP duration & $58.92 \pm 23.58$ & $62.60 \pm 25.99$ & 0.56 \\
& Mean PSP duration & $43.92 \pm 19.12$ & $43.50 \pm 17.57$ & 0.90 \\
& Max PSP latency & $89.13 \pm 21.75$ & $80.10 \pm 32.65$ & 0.21 \\
& Min PSP latency & $95.13 \pm 18.92$ & $89.45 \pm 34.63$ & 0.43 \\
& Mean PSP latency & $92.13 \pm 19.46$ & $84.77 \pm 33.10$ & 0.29 \\
Max PSP duration & $49.64 \pm 14.60$ & $64.98 \pm 23.49$ & 0.004 \\
TA & Min PSP duration & $37.16 \pm 10.85$ & $46.58 \pm 17.38$ & 0.01 \\
& Mean PSP duration & $43.40 \pm 12.38$ & $55.78 \pm 19.98$ & 0.005 \\
& Max PSP latency & $97.12 \pm 20.20$ & $87.80 \pm 20.04$ & 0.07 \\
& Min PSP latency & $100.78 \pm 20.48$ & $95.12 \pm 22.15$ & 0.30 \\
& Mean PSP latency & $98.95 \pm 19.46$ & $91.46 \pm 20.29$ & 0.15 \\
\hline
\end{tabular}

Notes: $P$-value for Student's $t$-test; mean \pm SD.

Abbreviations: Max, maximum; Min, minimum; SD, standard deviation. significantly higher in RLS patients than in controls at rest, while all PSP parameters were similar among patients and controls for the APB and gastrocnemius muscles. However, all PSP duration parameters were significantly shorter in patients than controls, although PSP latency parameters were similar for the TA muscle.

Ohayon et a ${ }^{14}$ reported BMI to represent an independent factor for RLS and found that a group with a BMI $>27 \mathrm{~kg} / \mathrm{m}^{2}$ had a 1.22-fold increased risk of RLS compared with a group with a BMI of $20-27 \mathrm{~kg} / \mathrm{m}^{2}$. In another study, using multivariable-adjusted models, Winter et $\mathrm{al}^{17}$ found that the odds ratio (OR) for a BMI $\geq 35 \mathrm{~kg} / \mathrm{m}^{2}$ was 1.35 for RLS in women. Gao et $\mathrm{al}^{26}$ further reported that the multivariateadjusted OR for RLS was 1.42 for participants with a BMI $>30$ versus $<23 \mathrm{~kg} / \mathrm{m}^{2}$, and 1.60 for the highest quintiles of waist circumference versus the lowest.

Isak et $\mathrm{a}^{23}$ found that the minimum, maximum, and mean FWL of the ulnar and tibial nerves were statistically similar when compared between RLS patients and controls. Electrical stimulation to elicit the H-reflex measures the efficacy of synaptic transmission as the stimulus travels in afferent (Ia sensory) fibers through the motor neuron pool of the corresponding muscle to the efferent (motor) fibers. ${ }^{27} \mathrm{H}$ reflexes are, therefore, of significant value for proximal lesions, nerve root lesions, and plexus lesions. The sensitivity of the test, and the value of amplitude measurements (H:M ratio), is further increased in cases involving unilateral pathology. ${ }^{28}$

An increased H/M ratio is noteworthy because this shows resemblance with the Babinski response described previously. ${ }^{29}$ While Wechsler et al ${ }^{30}$ reported that $\mathrm{H} / \mathrm{M}$ ratios were increased in RLS patients during the night, Bucher et $\mathrm{al}^{31}$ reported that $\mathrm{H} / \mathrm{M}$ ratios were normal in RLS patients. In a study involving RLS and PLMD patients and healthy controls, the Soleus H-reflex was investigated by tibial nerve electrical stimulation. ${ }^{24}$ These authors reported that there were no statistically significant differences in H-reflex maximum amplitude, in $\mathrm{M}$ response maximum amplitude, or $\mathrm{H} / \mathrm{M}$ ratio, when compared between patients and controls, and stated that the probable causal mechanisms were changes in the function of the descending spinal tracts or interneural circuitry changes at the spinal level. ${ }^{24}$ Another study reported that H-reflexes were suppressed during the PSP but facilitated during the resting state; the authors of this study concluded that while spinal motor neurons are excitable by antidromic impulses, the corticospinal impulse is inhibited to produce the PSP. ${ }^{32}$ Similar H-wave latency in patients and controls, at rest and during forced plantar flexion, suggests that there are an equal 
number of active Group Ia afferents during the excitation of motor neurons, and that there is no defect in the afferent system. The fact that we observed a higher $\mathrm{H}$-wave maximum amplitude and $\mathrm{H} / \mathrm{M}$ ratio in our patients than in our controls at rest was probably due to a reduction in spinal segment inhibition. Higher M-wave latency in patients than in controls during forced plantar flexion, but not at rest, indicates that voluntary motor activity increases the level of inhibition on reflex activity at the spinal level, similar to the relief of symptoms with stretching or moving the legs in RLS.

PSP is a valuable and noninvasive tool for evaluating nerve conduction in small myelinated fibers and represents a highly useful addition for neurophysiology nerve examinations; reduced duration of PSP is known to be related to disturbed inhibition. ${ }^{33,34}$ Isak et $\mathrm{al}^{23}$ reported that PSP latency was prolonged in patients with RLS, although PSP duration was similar in the APB muscle among patients and controls. However, these authors also reported prolonged latency and reduced duration in the TA muscle in patients with RLS and concluded that abnormalities in PSP parameters were caused by dysfunctions in the different spinal interneuron groups. Öz et $\mathrm{al}^{35}$ studied 25 RLS patients and 25 healthy volunteers to investigate PSP parameters and examine the effects of pramipexole treatment. These authors found that TA muscle PSP latency was prolonged and that PSP duration was reduced in RLS patients compared with controls. Furthermore, they reported that the PSP duration of the $\mathrm{APB}$ and TA muscles were prolonged following treatment and concluded that small fiber neuropathy may be involved and that pramipexole may regulate the inhibitory mechanisms associated with RLS. In a recent study investigating the relationships between RLS, small fiber neuropathy, and PSP parameters, it was found that mean PSP latencies of the extensor digitorum brevis muscle were similar in patients and controls, whereas PSP duration was significantly prolonged in patients with RLS compared with controls. ${ }^{36}$ These authors also reported that descending modulator fibers in the spinal circuit may be associated with hypothalamic dopaminergic projections and may be responsible for sensorimotor symptoms in patients with RLS. ${ }^{36}$

\section{Limitations and strengths of the study}

The most important limitation of this study is external validity. The results may not be generalizable for the general population because the study was conducted in a university hospital with patients and healthy controls, and also lacked neurophysiological investigations designed to probe central nervous system excitability. Other issues are related to the reproducibility of the techniques and our small study groups. However, the main strengths of our study are as follows: 1) our comparison of neurophysiological outcomes between RLS patients and healthy controls; 2) the different electrophysiological parameters, which were used; 3 ) the comparison of parameters relating to different nerves and muscles, which innervate the upper and lower extremities.

\section{Conclusions}

Only limited data are available, which describe or evaluate the neurophysiological findings of RLS patients. In this study, we aimed to determine changes in electrophysiological tests in Turkish RLS patients compared with healthy volunteers, including FWL, PSP, and H-reflex. The findings of this study suggest that there may be a reduction in spinal segmental inhibition at the L4-L5-S1 level, that the mechanisms of inhibition at the L4-L5 level and the S1 level may be different, and that there may not be any pathology in the peripheral nerves. Further prospective studies with larger cohorts are now needed to evaluate the pathophysiology of RLS with different neurophysiological assessment tools.

\section{Acknowledgment}

Written consent was obtained from all participants after they had been fully informed about the nature and intentions of the study.

\section{Disclosure}

The authors report no conflicts of interest in this work.

\section{References}

1. Allen RP, Picchietti D, Hening WA, Trenkwalder C, Walters AS, Montplaisi J. Restless legs syndrome: diagnostic criteria, special considerations, and epidemiology. A report from the restless legs syndrome diagnosis and epidemiology workshop at the National Institutes of Health. Sleep Med. 2003;4(2):101-119.

2. Allen RP, Walters AS, Montplaisir J, et al. Restless legs syndrome prevalence and impact: REST general population study. Arch Intern Med. 2005;165(11):1286-1292.

3. Yeh P, Walters AS, Tsuang JW. Restless legs syndrome: a comprehensive overview on its epidemiology, risk factors, and treatment. Sleep Breath. 2012;16(4):987-1007.

4. Berger K, Luedemann J, Trenkwalder C, John U, Kessler C. Sex and the risk of restless legs syndrome in the general population. Arch Intern Med. 2004;164(2):196-202

5. Innes KE, Selfe TK, Agarwal P. Prevalence of restless legs syndrome in North American and Western European populations: a systematic review. Sleep Med. 2011;12(7):623-634.

6. Garcia-Borreguero D, Williams AM. An update on restless legs syndrome (Willis-Ekbom disease): clinical features, pathogenesis and treatment Curr Opin Neurol. 2014;27(4):493-501.

7. Allen RP, Stillman P, Myers AJ. Physician-diagnosed restless legs syndrome in a large sample of primary medical care patients in western Europe: prevalence and characteristics. Sleep Med. 2010;11(1):31-37. 
8. Walters AS, LeBrocq C, Dhar A, et al. Validation of the International Restless Legs Syndrome Study Group rating scale for restless legs syndrome. Sleep Med. 2003;4(2):121-132.

9. Allen R. Dopamine and iron in the pathophysiology of restless legs syndrome (RLS). Sleep Med. 2004;5(4):385-391.

10. Klingelhoefer L, Bhattacharya K, Reichmann H. Restless legs syndrome. Clin Med (Lond). 2016;16(4):379-382.

11. Dauvilliers Y, Winkelmann J. Restless legs syndrome: update on pathogenesis. Curr Opin Pulm Med. 2013;19(6):594-600.

12. Allen RP. Restless leg syndrome/Willis-Ekbom disease pathophysiology. Sleep Med Clin. 2015;10(3):207-214.

13. Tachibana N. Living with restless legs syndrome/Willis-Ekbom disease. Sleep Med Clin. 2015;10(3):359-367.

14. Ohayon MM, O’Hara R, Vitiello MV. Epidemiology of restless legs syndrome: a synthesis of the literature. Sleep Med Rev. 2012;16(4): 283-295.

15. Winter AC, Berger K, Glynn RJ, et al. Vascular risk factors, cardiovascular disease, and restless legs syndrome in men. Am J Med. 2013;126(3): 228-235.e222.

16. Schlesinger I, Erikh I, Avizohar O, Sprecher E, Yarnitsky D. Cardiovascular risk factors in restless legs syndrome. Mov Disord. 2009;24(11): 1587-1592.

17. Winter AC, Schürks M, Glynn RJ, et al. Vascular risk factors, cardiovascular disease, and restless legs syndrome in women. Am JMed. 2013;126(3): 220-227.e222.

18. Lanza G, Cantone M, Lanuzza B, et al. Distinctive patterns of cortical excitability to transcranial magnetic stimulation in obstructive sleep apnea syndrome, restless legs syndrome, insomnia, and sleep deprivation. Sleep Med Rev. 2015;19:39-50.

19. Magalhaes SC, Kaelin-Lang A, Sterr A, do Prado GF, Eckeli AL, Conforto AB. Transcranial magnetic stimulation for evaluation of motor cortical excitability in restless legs syndrome/Willis-Ekbom disease. Sleep Med. 2015;16(10):1265-1273.

20. Michaud M, Paquet J, Lavigne G, Desautels A, Montplaisir J. Sleep laboratory diagnosis of restless legs syndrome. Eur Neurol. 2002;48(2): $108-113$.

21. Lanza G, Bachmann CG, Ghorayeb I, Wang Y, Ferri R, Paulus W. Central and peripheral nervous system excitability in restless legs syndrome. Sleep Med. 2017:49-60.
22. Trenkwalder C, Paulus W, Walters AS. The restless legs syndrome. Lancet Neurol. 2005;4(8):465-475.

23. Isak B, Uluc K, Salcini C, Agan K, Tanridag T, Us O. A neurophysiological approach to the complex organisation of the spine: F-wave duration and the cutaneous silent period in restless legs syndrome. Clin Neurophysiol. 2011;122(2):383-390.

24. Rijsman RM, Stam CJ, Weerd AW. Abnormal H-reflexes in periodic limb movement disorder; impact on understanding the pathophysiology of the disorder. Clin Neurophysiol. 2005;116(1):204-210.

25. International restless legs syndrome study group. IRLSSG diagnostic criteria for RLS. Available from: http://irlssg.org/diagnostic-criteria/. 2012. Accessed January 23, 2017.

26. Gao X, Schwarzschild MA, Wang H, Ascherio A. Obesity and restless legs syndrome in men and women. Neurology. 2009;72(14):1255-1261.

27. Capaday C. Neurophysiological methods for studies of the motor system in freely moving human subjects. J Neurosci Methods. 1997; 74(2):201-218.

28. Burke D. Clinical uses of $H$ reflexes of upper and lower limb muscles. Clin Neurophysiol Pract. 2016;1:9-17.

29. Smith RC. Relationship of periodic movements in sleep (nocturnal myoclonus) and the Babinski sign. Sleep. 1985;8(3):239-243.

30. Wechsler LR, Stakes JW, Shahani BT, Busis NA. Periodic leg movements of sleep (nocturnal myoclonus): an electrophysiological study. Ann Neurol. 1986;19(2):168-173.

31. Bucher SF, Trenkwalder C, Oertel WH. Reflex studies and MRI in the restless legs syndrome. Acta Neurol Scand. 1996;94(2):145-150.

32. Leis AA, Stetkarova I, Beric A, Stokic DS. Spinal motor neuron excitability during the cutaneous silent period. Muscle Nerve. 1995; 18(12):1464-1470.

33. Leis AA. Conduction abnormalities detected by silent period testing. Electroencephalogr Clin Neurophysiol. 1994;93(6):444-449.

34. Logigian EL, Plotkin GM, Shefner JM. The cutaneous silent period is mediated by spinal inhibitory reflex. Muscle Nerve. 1999;22(4): $467-472$.

35. Öz O, Erdoğan Ç, Yücel M, et al. Effect of pramipexole on cutaneous-silent-period parameters in patients with restless legs syndrome. Clin Neurophysiol. 2012;123(1):154-159.

36. Han J-K, Oh K, Kim B-J, et al. Cutaneous silent period in patients with restless leg syndrome. Clin Neurophysiol. 2007;118(8):1705-1710.
Neuropsychiatric Disease and Treatment

\section{Publish your work in this journal}

Neuropsychiatric Disease and Treatment is an international, peerreviewed journal of clinical therapeutics and pharmacology focusing on concise rapid reporting of clinical or pre-clinical studies on a range of neuropsychiatric and neurological disorders. This journal is indexed on PubMed Central, the 'PsycINFO' database and CAS,

\section{Dovepress}

and is the official journal of The International Neuropsychiatric Association (INA). The manuscript management system is completely online and includes a very quick and fair peer-review system, which is all easy to use. Visit http://www.dovepress.com/testimonials.php to read real quotes from published authors. 